\title{
Giant Left Atrial Myxoma in an Elderly Man: Case Report
}

\author{
Darya A. Faqi Mahmoud1, Jaafar S. Aldoori², Abdulsalam Y. Taha ${ }^{{ }^{*}}$ \\ ${ }^{1}$ Department of Cardiac Surgery, Sulaimania Center for Heart Diseases (SCHD), Sulaimania, Iraq \\ ${ }^{2}$ Department of Cardiology, Sulaimania Center for Heart Diseases (SCHD), Sulaimania, Iraq \\ ${ }^{3}$ Department of Cardiothoracic and Vascular Surgery, Faculty of Medical Sciences, School of Medicine, \\ University of Sulaimania and Sulaimania Teaching Hospital, Sulaimania, Iraq \\ Email: *salamyt1963@hotmail.com
}

Received 20 February 2014; revised 15 March 2014; accepted 6 April 2014

Copyright (C) 2014 by authors and Scientific Research Publishing Inc.

This work is licensed under the Creative Commons Attribution International License (CC BY).

http://creativecommons.org/licenses/by/4.0/

(c) (i) Open Access

\section{Abstract}

Left atrial myxomas (LAM), the most common primary tumours of the heart are unusual or rare in the elderly. Moreover, elderly patients often present with non-specific symptoms that are frequently overlooked in the absence of a supporting cardiac history which makes an early diagnosis challenging. Herein, we reported large LAM in 70-year-old Iraqi Kurdish male who was presented with minimal obstructive symptoms and the diagnosis was not suspected clinically but discovered by trans-thoracic echocardiography (TTE) followed by successful surgical excision. Although atrial myxomas are benign, they have potential serious complications which mandate prompt therapy. Due to low morbidity and mortality besides its excellent outcome even in the elderly, surgery is the preferred choice of treatment for LAMs.

\section{Keywords}

Left Atrial Myxoma, Elderly, Cerebral Embolism, Echocardiography

\section{Introduction}

Left atrial myxoma (LAM) is histologically benign and is the most common primary tumour of the heart [1]. It accounts for $80 \%$ of all cardiac tumours [2]. It could be seen in patients between 3 - 83 years of age, with the majority presenting in fifth decade of life as sporadic cases (90\%) and second decade as familial cases (10\%) [3]. Differential diagnosis of atrial myxoma includes pedunculated thrombus, metastatic sarcoma and melanoma in left atrium [3]. Atrial myxoma in older people is considered to be unusual, but with the advent of newer imaging

"Corresponding author. 
modalities and longer life expectancy, the incidence of myxoma in older people has increased [1]. Atrial myxoma may be asymptomatic, in contrast, symptomatic cases may present with obstruction of cardiac blood flow, embolic phenomena and constitution symptoms [4]. Elderly patients often present with non-specific symptoms that are often overlooked in the absence of a supporting cardiac history which makes an early diagnosis challenging [3]. Herein, we reported large LAM in 70-year-old Iraqi Kurdish male who was presented with minimal obstructive symptoms and the diagnosis was not suspected clinically but discovered by trans-thoracic echocardiography (TTE) followed by successful surgical excision. The case is presented with review of the relevant literature.

\section{Clinical Summary}

A man of 70, a known case of reducible right inguinal hernia of 2 months duration was referred to Cardiology Department of Sulaimania Center for Heart Diseases (SCHD) on August 8, 2012 for evaluation of his cardiac status prior to general anaesthesia. He used to complaint of dyspnoea on exertion and dizziness for few years. His past medical history was insignificant and was an ex-smoker. Physical examination revealed right-sided reducible inguinal hernia of moderate size whereas cardiac examination displayed an irregularly irregular pulse with a rate of $100 \mathrm{bpm}$, Bp of 100/60 mmHg and an apical systolic murmur. The patient was previously prescribed digoxin and aspirin probably for a diagnosis of atrial fibrillation (AF). Blood tests were normal. ESR = $35 \mathrm{~mm}$ /hour. Chest radiograph was also normal. Electrocardiography (ECG) showed features of slow AF. TTE (Figures 1(a)-(d)) revealed big irregular mass occupying the entire left atrium (LA) with a pedicle attached to the left side of the inter-atrial septum prolapsing into the mitral valve (MV) in diastole. This appearance was

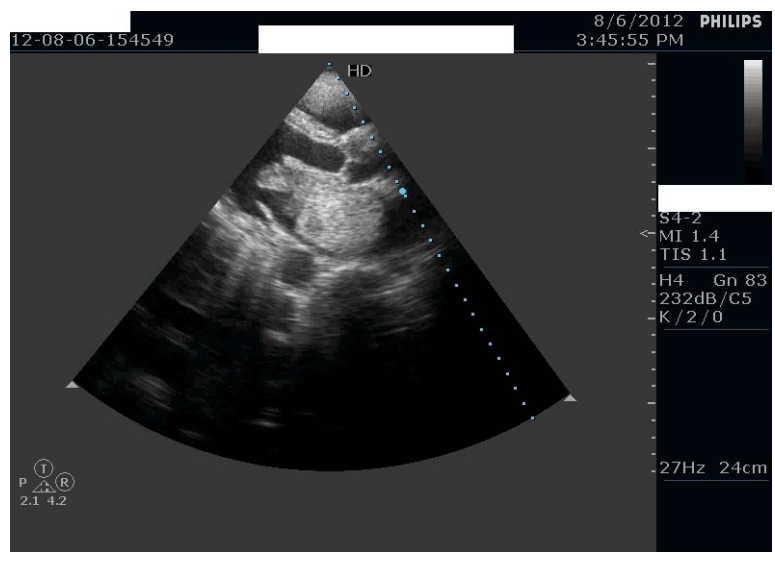

(a)

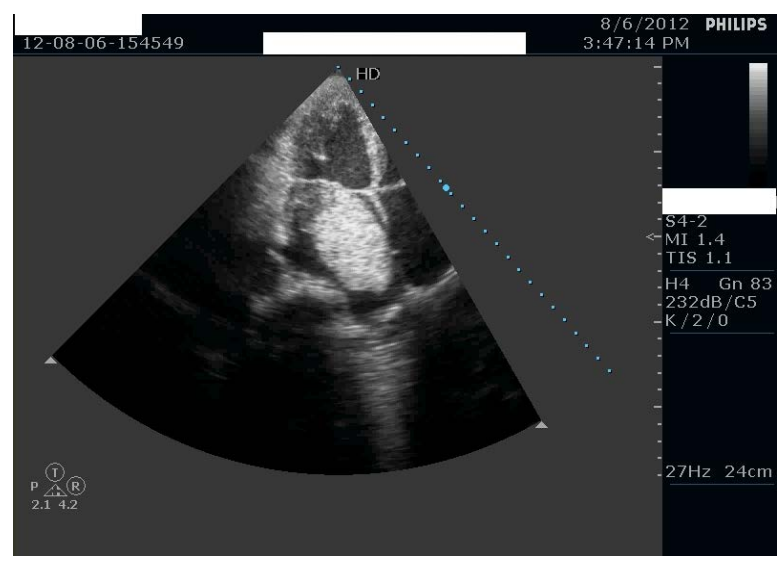

(c)

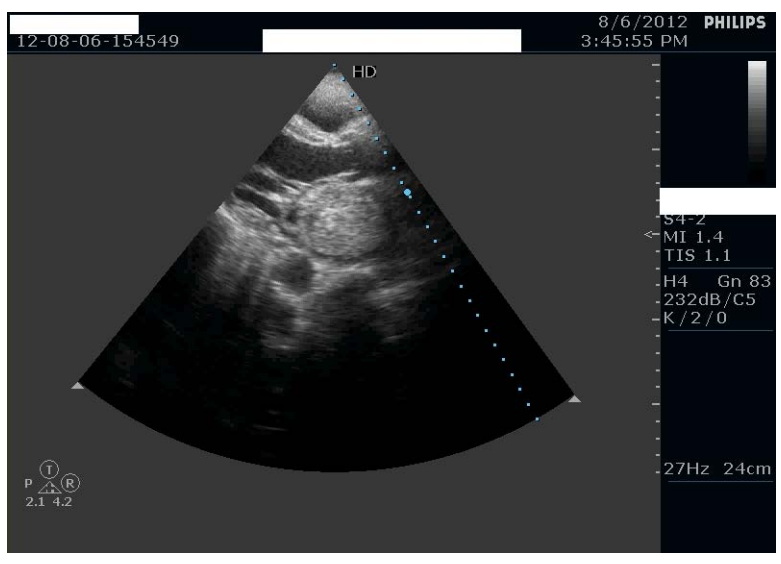

(b)

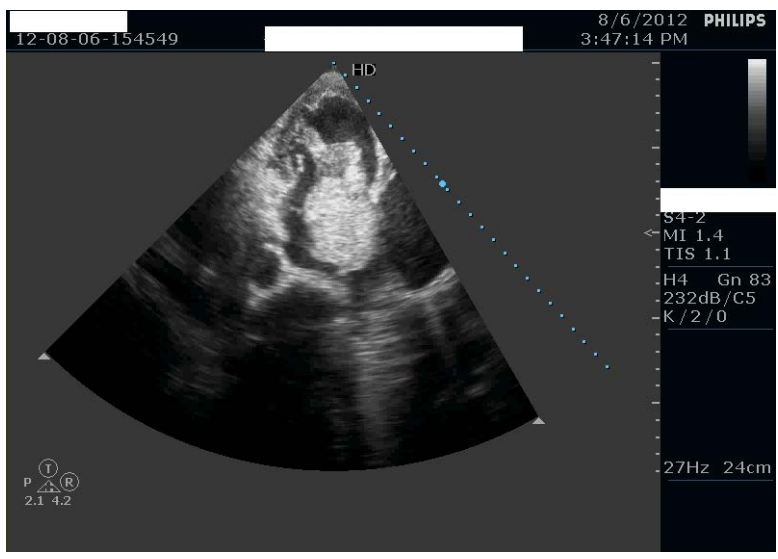

(d)

Figure 1. (a) Preoperative echocardiogram in diastole; (b) Preoperative echocardiogram in systole; (c) Preoperative echocardiogram, four chamber view in systole. (d) Preoperative echocardiogram, four chamber view in diastole. 
highly suggestive of atrial myxoma, which could explain the patient's symptoms. Other findings on echocardiography included dilation of LA and left ventricle and an ejection fraction of 50\%. Surgery was advised to relieve these symptoms and to avoid potential systemic embolization. Coronary angiography arranged prior to surgical intervention to rule out coronary artery disease was normal. Operative treatment was carried out via median sternotomy, total cardiopulmonary bypass (CPB) and combined left and right atriotomies. The mass was successfully excised with a piece of the inter-atrial septum. The defect in the septum was closed by poly-tetraflouro-ethylene (PTFE) patch. The aortic cross clamp time was 28 minutes. Pathological analysis of the atrial mass revealed it to be $7.5 \times 4.5 \times 2.5 \mathrm{~cm}$ atrial myxoma (Figure 2). The postoperative course was uneventful. A follow-up echocardiography (Figure 3(a) and Figure 3(b)) showed no evidence of atrial myxoma and the MV leaflets separated normally.

\section{Comment}

Pathology: Atrial myxomas are benign tumours. Two thirds of them arise in the left atrium. Other locations are right atrium (next commonest), ventricles, superior vena cava or pulmonary veins. In 5 percent of cases, myx-

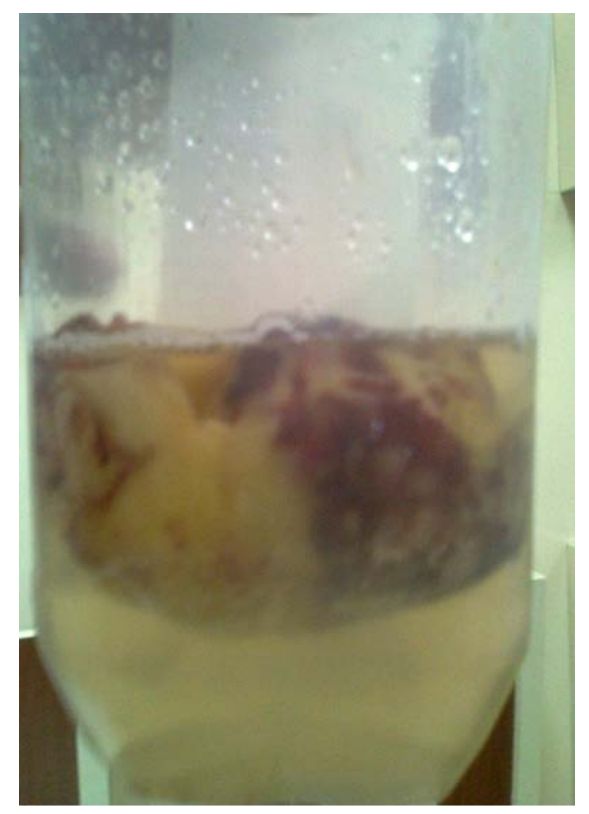

Figure 2. Operative specimen.

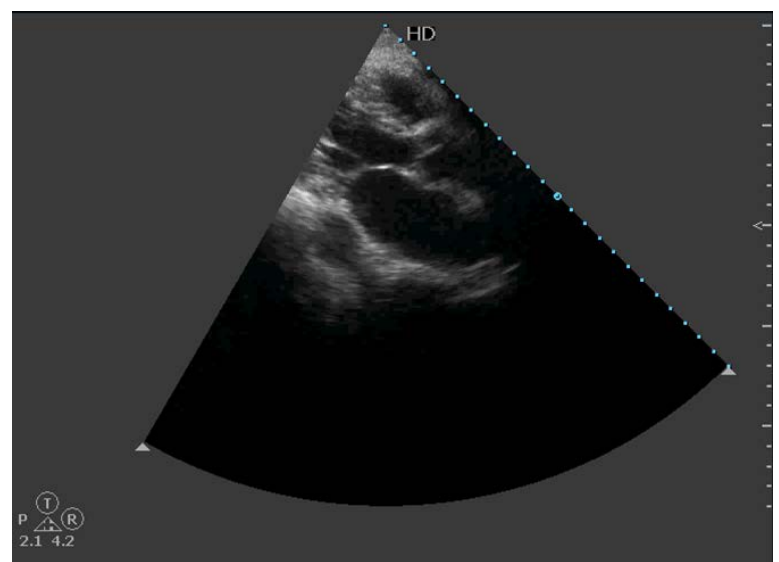

(a)

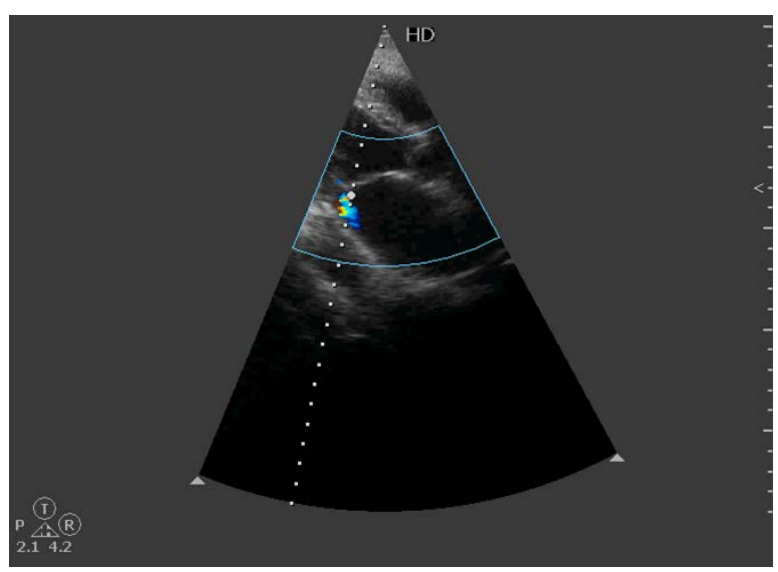

(b)

Figure 3. (a) Postoperative echocardiogram; (b) Postoperative colour doppler. 
omas can be multiple [3]. Most myxomas produce symptoms when they weigh greater than seventy grams [3]. LAM is considered giant, as in our case, when it occupies the entire LA [5].

Incidence: Atrial myxomas are found in approximately $14 \%$ - 20\% of the population [2]. In Iraq, reported cases are few. Al Ani et al. reported a case of small right atrial myxoma $1 \times 0.5 \mathrm{~cm}$ in size associated with Ebstein anomaly in a male of 45 which was not diagnosed preoperatively [6]. Al-Obaidi and Al-kashaab posted a video demonstrating excision of LAM in Ibn-Albitar Center for Cardiac Surgery [7].

Age: With the advent of newer imaging modalities and longer life expectancy, the incidence of myxoma in older people has increased [1]. A recent review reported 63 individuals with cardiac myxoma aged 68 to 88 [1]. To the best of our knowledge, the oldest person with atrial myxoma who has undergone surgical resection was a Japanese man of 90 [1].

Symptomatology: Common symptoms include chest pain, dyspnea, orthopnea, peripheral embolism or syncope [2]. However, atrial myxoma is among the great mimickers of clinical medicine. It should be put on a list of differential diagnoses for heart failure even in older people [1]. Our patient had minimal obstructive symptoms (dizziness and effort dyspnoea). Both could be related to his age and therefore, they were overlooked. Associated AF might be a complication of LAM.

Diagnosis: Precise diagnosis of LAM on the basis of clinical findings is often not made in the elderly patient as the symptoms are often attributed to "generalized arteriosclerosis of the elderly" [8]. In our case as in many previous reports, the diagnosis was not suspected clinically and was made later by TTE. LAM, although rarely observed in the elderly, may be diagnosed easily by means of echocardiography [9].

Treatment: The classical management and the only definitive treatment [3] of this disease is prompt surgical removal. However, there may be exceptions to this traditional dogma. Kay and Chow from Hong Kong reported an 85-year-old man with a calcified LAM and features of COPD and congestive heart failure managed conservatively as he considered cardiac surgery of high risk and refused operation. Moreover, there were no features of intra-cardiac obstruction, embolism or progressive growth on serial echocardiography [10]. Anneka and Kumar believe that conservative management is of limited value in symptomatic patients with large myxomas. However, a conservative strategy with TTE/TOE monitoring \& anticoagulation is favoured in high operative risk patients, asymptomatic patients, and slow growing atrial myxomas [3]. In our case, despite minimal symptoms and advanced age, surgery was indicated due to the size of the tumour which may result in fatal valve obstruction at anytime and the high risk of cerebral emboli due to LAM combined with AF and the reported excellent outcome and low risk of surgery for LAM even in the elderly [11].

Morbidity and mortality: Cardiac myxomas in older people were surgically resected with mortality of $1.7 \%$ [1].

Prognosis: LAM, if left untreated, is inexorably progressive and usually fatal. In contrast, calcified left atrial myxoma may exhibit a quiescent phase. Tumor calcification, slow growth potential, and the absence of intracardiac obstruction may correlate with a better outcome in the elderly patient [10].

\section{Conclusion}

Atrial myxoma in older people is unusual. Elderly patients often present with non-specific symptoms that are frequently overlooked in the absence of a supporting cardiac history which makes an early diagnosis challenging. Surgery is the preferred choice of treatment for LAMs with excellent outcome even in the elderly.

\section{Consent}

Written informed consent was obtained from the patient for publication of this case report and any accompanying images.

\section{Competing Interests}

The authors declare that they have no competing interests.

\section{References}

[1] Matsumura, Y., Nakashima, Y., Noguchi, T., Baba, Y., Wada, M., Hayashi, K., et al. (2013) Giant Left Atrial Myxoma in a Nonagerian. Journal of the American Geriatrics Society, 61, 169-170. http://dx.doi.org/10.1111/jgs.12059 
[2] Vicari, R.M., Polanco, E., Schechtmann, N., Santiago, J.O., Shaurya, K., Halstead, M., et al. (2009) Atrial Myxoma Presenting with Orthostatic Hypotension in an 84-Year-Old Hispanic Man: A Case Report. Journal of Medical Case Reports, 3, 9328. http://dx.doi.org/10.1186/1752-1947-3-9328

[3] Biswas, A. and Thakur, A.K. (2008) An Unusual Presentation of Atrial Myxoma in an Elderly Patient: A Case Report. Cases Journal, 1, 384. http://dx.doi.org/10.1186/1757-1626-1-384

[4] Tobe, M., Reddy, S. and Kondamudi, V. (2011) Atrial Myxoma Presenting as Asymptomatic Left Atrial Mass: A Case Report. Middle East Journal of Family Medicine, 9, 31-32.

[5] Bajraktari, G., Emini, M., Berisha, V., Gashi, F., Beqiri, A., Zahiti, B., et al. (2006) Giant Left Atrial Myxoma in an Elderly Patient: Natural History over a 7-Year Period. Journal of Clinical Ultrasound, 34, 461-463. http://dx.doi.org/10.1002/jcu.20265

[6] Al Ani, H., Al Ani, F. and Mahbuba, W. (2006) Adult Ebstein Anomaly with Right Atrial Myxoma. Iraqi Postgraduate Medical Journal, 5, 240-245.

[7] Al-Obaidi, W. and Al-kashaab, S. (2014) Removal of Left Atrial Myxoma through Left and Right Atriotomy Incision. https://www.facebook.com/photo.php?v=531762700217667

[8] Davison, E.T., Mumford, D., Zaman, Q. and Horowitz, R. (1986) Left Atrial Myxoma in the Elderly. Report of Four Patients over the Age of 70 and Review of the Literature. Journal of the American Geriatrics Society, 34, 229-233.

[9] Guillet, P., Baconnet, C., Labrousse, A., Aigueperse, I., Andre, A., Grosgogeat, Y., et al. (1981) Left Atrial Myxoma in the Elderly: Diagnosis by M-Mode and Bidimensional Echocardiography. Journal of the American Geriatrics Society, 29, 453-459.

[10] Kay, J.F. and Chow, W.H. (2002) Long-Term Survival of Quiescent Left Atrial Myxoma in an Elderly Patient. The American Journal of Geriatric Cardiology, 11, 165-168. http://dx.doi.org/10.1111/j.1076-7460.2002.00831.x

[11] Fuwa, S., Saeki, S., Shinohara, A., Kataka, H., Naito, K. and Hirose, H. (1991) A Case of Left Atrial Myxoma in the Elderly (77-Year-Old). Kokyu to Junkan, 39, 399-401. 